CLINICAL STUDY

\title{
The usefulness of sonographic features in selection of thyroid nodules for biopsy in relation to the nodule's size
}

\author{
Bożena Popowicz ${ }^{1}$, Mariusz Klencki ${ }^{1}$, Andrzej Lewiński ${ }^{2}$ and Dorota Słowińska-Klencka ${ }^{1}$ \\ ${ }^{1}$ Department of Morphometry of Endocrine Glands and ${ }^{2}$ Clinic of Endocrinology and Metabolic Diseases, Chair of Endocrinology and Metabolic Diseases, \\ Medical University of Lodz, Sterling Street No 5, 91-425 Lodz, Poland
}

(Correspondence should be addressed to D Slowinska-Klencka; Email: dsk@tyreo.am.lodz.pl)

\begin{abstract}
Objective: To evaluate the efficacy of selected ultrasound (US) features of thyroid focal lesions useful for establishing indications for fine-needle aspiration biopsy (FNAB) with regard to the lesion's size.

Methods: US imaging features of 1141 thyroid nodules (shape, echogenicity, pattern of blood flow, presence of microcalcifications and the presence of other nodules in the thyroid) and their palpability were compared with the post-operative histopathological outcomes. The efficacy of the selected sets of the features was assessed for small nodules $(\mathrm{SN}) \leq 15 \mathrm{~mm}$ and large nodules $(\mathrm{LN})>15 \mathrm{~mm}$, as well as separately for nodules $\leq 10 \mathrm{~mm}$.

Results: Logistic regression analysis showed that in SN hypoechogenicity (odds ratios, OR: 3.18), microcalcifications (OR: 19.12), solitary occurrence (OR: 3.29) and height-to-width ratio $\geq 1$ (OR: 8.57 ) were independent risk factors for malignancy. The optimal set of small lesions that should be biopsied includes all lesions presenting at least one of the above-mentioned features (sensitivity $98 \%$, specificity 44\%). In the LN group, the selection criteria based on the shape of lesions and hypoechogenicity were less sensitive than in the SN group, but they allowed further reduction in the number of performed FNABs. Large nodules primarily selected for FNAB should be hypoechoic, more tall then wide or contain microcalcifications (sensitivity $84 \%$, specificity $72 \%$ ).

Conclusions: The obtained results provide rationale for using features from the US examination in selecting both small and large nodules for FNAB. In the case of LN, the usefulness of sonographic features is less sensitive, but more specific than in the case of SN.
\end{abstract}

European Journal of Endocrinology 161 103-111

\section{Introduction}

In recent years, the spread of thyroidological diagnostics using high-definition ultrasound imaging (US) has resulted in a growing number of patients with revealed small focal lesions in the thyroid. Such lesions are often visualised in examined patients ranging in frequency from $20 \%$ to - according to some data - more than $60 \%$ $(1,2)$. Our data are concordant with these observations. At our department, the percentage of patients with thyroid lesions not larger than $15 \mathrm{~mm}$ in maximal diameter reaches $67 \%$ of all diagnosed with US. In $\sim 30 \%$ of examined patients, only nodules not larger than $10 \mathrm{~mm}$ are revealed (3).

The clinical significance of small thyroid lesions has not been clarified. At first it was assumed that such lesions could be left cytologically undiagnosed in patients without history positive for the high risk of thyroid carcinoma (as with previous neck irradiation or others; 2,4$)$. Some recent papers have brought convincing data on high percentage of carcinomas (some of them with extrathyroidal invasion) in small lesions subjected to fine-needle aspiration biopsy (FNAB; 5-11).

The precise indications for FNAB of small thyroid lesions are still being investigated. The main criteria considered include sonographic features like the size, shape and echogenicity of lesions, the vascular pattern in Doppler imaging, the presence of microcalcifications and appearance of lesion's borders (12-16). There is some discrepancy in available data as it comes to the optimal selection of these criteria, as well as the influence of the proposed criteria on the number of biopsies to be performed.

The problem of proper selection of nodules for FNAB is particularly relevant in countries with high number of patients with multinodular goitre, i.e. in areas of iodine deficiency or areas of recently corrected deficiency like Poland $(3,17,18)$. At our department, any focal lesions in the thyroid gland were found in $77 \%$ of 
the patients subjected to US examination, in the majority of those patients $(78 \%)$, multiple nodules were revealed (3). In such settings often, even selection between several larger lesions must be made.

The aim of our paper is to evaluate the efficacy of selected US features of thyroid focal lesions useful for establishing indications for FNAB with regard to the lesion's size.

\section{Materials and methods}

The study included 1141 nodules diagnosed at our centre between years 2000 and 2005 in 672 patients (mean age \pm s.D.: $49.5 \pm 11.4$ years) for which there were available US features, data on palpability and postoperative histopathological outcomes. Patients were referred to thyroid surgeons for large multinodular goitre (regardless of benign FNAB - in majority of cases) or because of suspected or malignant lesion diagnosed cytologically. The study included not only biopsied nodules, but also all accompanying lesions described in US examination with known histopathological diagnosis. All the nodules were divided into malignant tumours and benign lesions on the basis of histopathological outcome. No patient included in this series had a history of external or ionising radiation or previous diagnosis of thyroid malignancy.

All the US examinations were performed by the team of three physicians with at least five years experience, with the same equipment, namely Elegra Advanced (Siemens Medical Systems Inc., Issaquah, WA, USA) with a $7.5 \mathrm{MHz}$ linear transducer and power Doppler capability. Its state-of-the-art technology allows visualisation of tiny lesions within the thyroid (diameter $\geq 1 \mathrm{~mm}$ ). The following lesion features obtained through the US examination were analysed: shape (categorised by the ratio of anteriorposterior dimension (height) to the transverse dimension (width) of lesion, with values of the ratio $\geq 1$ in one category and $<1$ in the other); echogenicity (solid hypoechoic versus another appearance); pattern of blood flow in power Doppler imaging (intranodular vascular pattern versus other patterns); the presence of intranodular microcalcifications; and the presence of other lesions in the thyroid (Figs 1-4). Because of a retrospective design of the study in the case of two evaluated features - the pattern of blood flow and the shape of lesion - the analysis included only 316 and 210 lesions respectively. The assessment of pattern of blood flow was not performed from the beginning of the analysed period, and in some cases only single diameter of lesion was examined and it was not possible to calculate the shape index. The lesions margins were not described in a uniform fashion and could not be included in the analysis. Additionally, palpability of examined lesions was also considered.

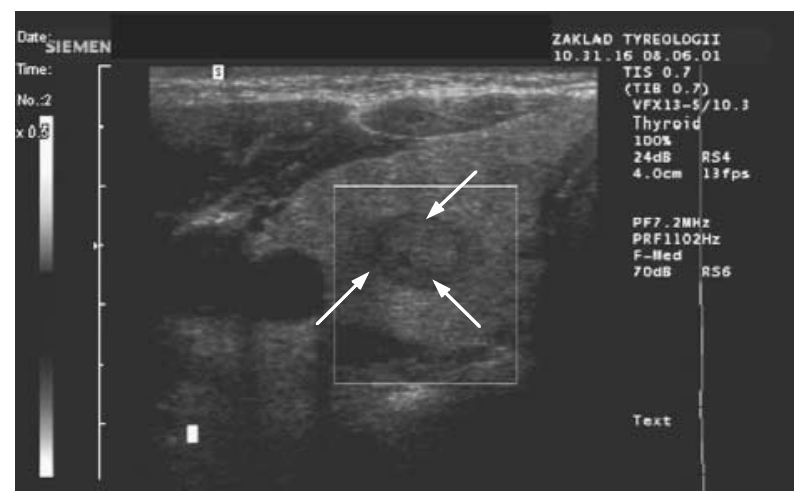

Figure 1 Hypoechoic nodule.

The efficacy of the above-mentioned features in prediction of malignancy was evaluated separately for small nodules (SNs) - lesions with the maximal diameter not longer than $15 \mathrm{~mm}$ and large nodules (LNs) - lesions with the maximal diameter longer than $15 \mathrm{~mm}$. Additionally, in SN group, the lesions with diameters not exceeding $10 \mathrm{~mm}$ and lesions with diameters 11-15 mm were distinguished. Moreover, the impact of various criteria based on a combination of the above-mentioned features on the potential efficacy of cytological examination in diagnosing thyroid malignancy and optimisation of number of performed FNAB was evaluated.

The comparison of frequency distributions was performed by $\chi^{2}$ test. Multivariate (logistic regression analysis) odds ratios (OR), with 95\% confidence intervals, were calculated to assess the relevance of the US features and lesion palpability to predict histological outcome. The diagnostic value of selected criteria was also assessed in terms of sensitivity, specificity, positive predictive value and negative predictive value. For the evaluation of the sets of US features, only lesions with data available on all analysed features were included. The value of 0.05 was assumed as the level of significance.

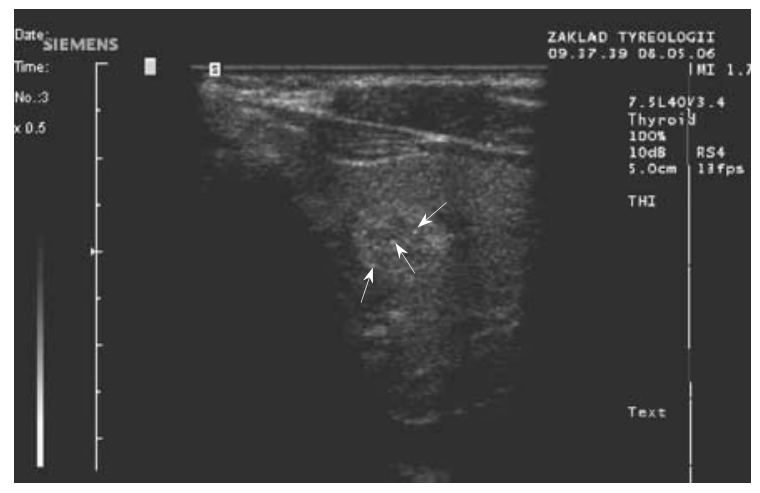

Figure 2 Microcalcifications in thyroid nodule. 


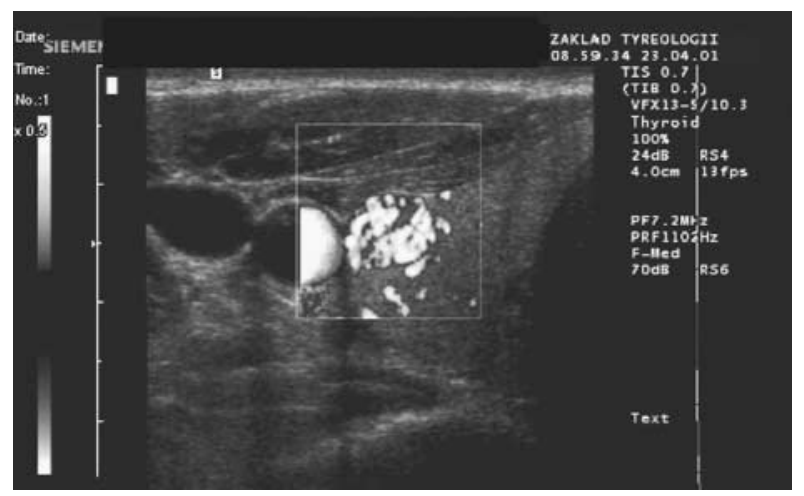

Figure 3 Nodule with intranodular vascular pattern.

\section{Results}

The analysed lesions according to histopathological examination were non-neoplastic in 881 cases, follicular adenomas in 164 cases and malignant in 96 cases (72 papillary cancers, 11 medullary cancers, five oxyphilic cancers, two follicular cancers, four anaplastic cancers and two metastases). Among 96 cancers, there were 33 nodules with diameters below $10 \mathrm{~mm}$, of which five were found in patients operated because of multinodular goitre with no malignancy suspected. Between analysed lesions, there were $462(40.5 \%)$ LNs and 679 (59.5\%) SNs. The mean maximal diameter of nodules in LN group was $32.97 \pm 14.31 \mathrm{~mm}$ (mean \pm s.D.), median was $28 \mathrm{~mm}$, minimal size $15 \mathrm{~mm}$ and maximal size $80 \mathrm{~mm}$. Mean maximal diameter of nodules in SN group was $11.25 \pm 2.77 \mathrm{~mm}$ (mean \pm s.D.), median $10 \mathrm{~mm}$, minimal size $4 \mathrm{~mm}$ and maximal size $15 \mathrm{~mm}$. Size distribution of small lesions was as follows: maximal diameter of 351 lesions did not exceed $10 \mathrm{~mm}$ (mean maximal diameter was $8.93 \pm 1.24 \mathrm{~mm}$, median $9 \mathrm{~mm}$, minimal size $4 \mathrm{~mm}$ and maximal size $10 \mathrm{~mm}$ ) and there were 328 lesions with maximal diameter in range $11-15 \mathrm{~mm}$ (mean maximal diameter was $13.93 \pm 1.06 \mathrm{~mm}$, median $14 \mathrm{~mm}$, minimal size $11 \mathrm{~mm}$ and maximal size $15 \mathrm{~mm}$ ). Among lesions not exceeding $10 \mathrm{~mm}$, there were only several nodules with maximal diameter below $5 \mathrm{~mm}$, none of them was malignant.

It was found that the malignant lesions when compared with the benign ones were more frequently hypoechoic ( 61.5 vs $34.2 \% ; P<0.0001$ ), solitary ( 35.4 vs $21.1 \% ; P<0.005)$ and contained small calcifications (26.0 vs $3.1 \% ; P<0.0001)$. The ratio of height to width $\geq 1$ was found among the malignant lesions more frequently than in the case of the benign lesions (45.0 vs $10.0 \%, P<0.0001)$. The above-mentioned features (apart from the solitary occurrence of lesions) differentiated the malignant and benign nodules also within separately analysed groups LN and SN (hypoechogenicity $-P<0.0001, P<0.0005$ respectively; microcalcifications $-P<0.0001$ in both group; height-to-width ratio $\geq 1-P<0.005, P<0.0001$ respectively; Table 1 ). The solitary occurrence of lesions differed significantly between the malignant and benign lesions only in the group of $\mathrm{SN}(P<0.001)$. The intranodular vascular pattern was observed significantly more frequently in the large malignant nodules than in small ones $(75.0 \mathrm{vs}$ $33.3 \%, P<0.05)$, but no significant difference was observed between the malignant and benign lesions, irrespective of their size.

The detailed analysis of SN group divided into lesions with diameters $\leq 10 \mathrm{~mm}$ and $11-15 \mathrm{~mm}$ showed that features like hypoechogenicity, solitary occurrence and height-to-width ratio $\geq 1$ tended to be more sensitive in smaller nodules; on the contrary, the presence of microcalcifications was less sensitive (Table 2). Considering other parameters, neither palpability nor the size above $10 \mathrm{~mm}$ was significantly associated with the histological diagnosis. It was found in the $\mathrm{SN}$ group that the limitation of indications for FNAB to palpable lesions only or to the lesions larger than $10 \mathrm{~mm}$, according to some already proposed algorithms, would result in $63.5 \%$ of small $(<15 \mathrm{~mm})$ cancers not being examined in each case. Even if all lesions satisfying at least one of those two criteria had been examined, large percentage of small cancers $-48.1 \%$, including many invasive cases, would not have been biopsied.

The most sensitive single feature allowing selection of lesions for FNAB in both groups of nodules (SN and LN) was hypoechogenicity (Table 3). The selection of hypoechoic lesions only would have resulted in biopsying of $69.2 \%$ of cancers in $\mathrm{SN}$ group and $52.2 \%$ of cancers in LN. However, the specificity of that criterion was relatively low in SN, significantly lower than in the group of $\mathrm{LN}(57.9$ vs $77.8 \%, P<0.0001)$. On the other hand, the most specific criterion in both groups of lesions was the presence of microcalcifications $(>95 \%)$, but sensitivity of that feature was very low (29.5\% in $\mathrm{LN}$ and $23.1 \%$ in SN). It was also found that the ratio describing the shape of lesion showed higher sensitivity of revealing cancers in the SN group than in the LN group ( 55.1 vs $29.0 \%, P<0.02$ ), but lower

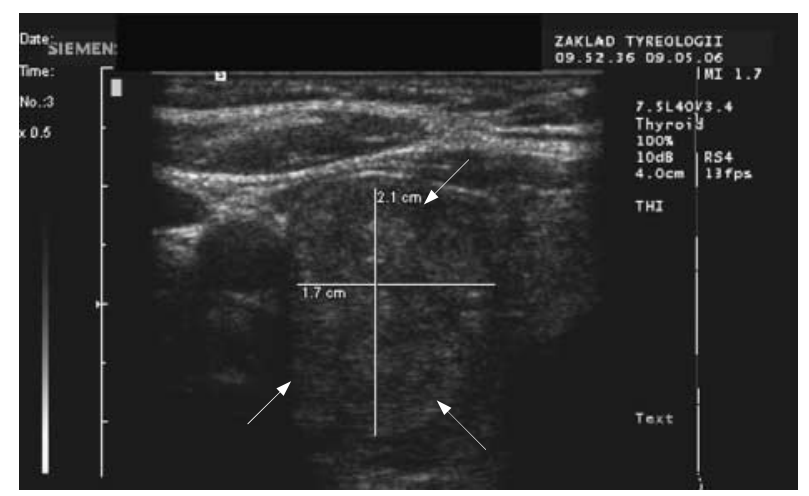

Figure 4 Nodule with anterior-posterior to the transverse dimension $\geq 1$. 
Table 1 Frequency analysis of sonographic features of thyroid lesions and their palpability with respect to size of nodules in groups of benign and malignant lesions.

\begin{tabular}{|c|c|c|c|c|c|c|}
\hline \multirow[b]{3}{*}{ Features of lesions } & \multicolumn{6}{|c|}{ Histopathological outcome } \\
\hline & \multicolumn{3}{|c|}{ Benign lesions } & \multicolumn{3}{|c|}{ Malignant lesions } \\
\hline & $\begin{array}{l}\text { All nodules } \\
(n=1045)\end{array}$ & $\begin{array}{l}\mathrm{LN} \\
(n=418)\end{array}$ & $\begin{array}{l}\mathrm{SN} \\
(n=627)\end{array}$ & $\begin{array}{l}\text { All nodules } \\
(n=96)\end{array}$ & $\begin{array}{l}\mathrm{LN} \\
(n=44)\end{array}$ & $\begin{array}{l}\mathrm{SN} \\
(n=52)\end{array}$ \\
\hline \multirow[t]{2}{*}{ Hypoechogenicity } & 357 & 93 & 264 & 59 & 23 & 36 \\
\hline & $34.2 \%$ & $22.2 \%$ & $42.1 \%$ & $61.5 \%$ & $52.3 \%$ & $69.2 \%$ \\
\hline \multirow[t]{2}{*}{ Solitary occurrence } & 221 & 112 & 109 & 34 & 15 & 19 \\
\hline & $21.1 \%$ & $26.8 \%$ & $17.4 \%$ & $35.4 \%$ & $34.1 \%$ & $36.5 \%$ \\
\hline \multirow[t]{2}{*}{ Presence of microcalcifications } & 32 & 18 & 14 & 25 & 13 & 12 \\
\hline & $3.1 \%$ & $4.3 \%$ & $2.2 \%$ & $26.0 \%$ & $29.5 \%$ & $23.1 \%$ \\
\hline \multirow[t]{2}{*}{ Intranodular vascular pattern ${ }^{\mathrm{a}}$} & $143 / 289$ & $84 / 142$ & $59 / 147$ & $14 / 27$ & $9 / 12$ & $5 / 15$ \\
\hline & $49.5 \%$ & $59.2 \%$ & $40.1 \%$ & $51.9 \%$ & $75.0 \%$ & $33.3 \%$ \\
\hline \multirow[t]{2}{*}{ Height/width $\geq 1^{\mathrm{b}}$} & $13 / 130$ & $4 / 76$ & $9 / 54$ & $36 / 80$ & $9 / 31$ & $27 / 49$ \\
\hline & $10.0 \%$ & $5.3 \%$ & $16.7 \%$ & $45.0 \%$ & $29.0 \%$ & $55.1 \%$ \\
\hline \multirow[t]{2}{*}{ Palpable } & 591 & 339 & 252 & 54 & & \\
\hline & $56.6 \%$ & $81.1 \%$ & $40.2 \%$ & $56.3 \%$ & $79.5 \%$ & $36.5 \%$ \\
\hline
\end{tabular}

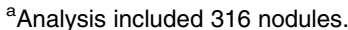

${ }^{\mathrm{b}}$ Analysis included 210 nodules.

specificity $(83.3$ vs $94.7 \%, P<0.05)$. The solitary occurrence of lesion was the feature more specific in SN group than in LN group (82.6 vs $73.2 \%, P<0.001$ ). There were no significant differences in the sensitivity or specificity of the other examined features between the $\mathrm{SN}$ and LN groups.

The results of multivariate logistic regression analysis of the features suggestive of malignant thyroid nodules are shown in Table 4. The diagnostic efficacy of the various feature combinations in selection of the thyroid lesions for FNAB is shown in Table 5. It was found in the $\mathrm{SN}$ group that the limitation of FNAB to the lesions, which showed at least one of the features significantly differentiating malignant and benign nodules, would

Table 2 The frequency of selected sonographic features and palpability of small benign and malignant thyroid lesions with respect to their size (above $10 \mathrm{~mm}$ in diameter or not exceeding $10 \mathrm{~mm}$ ).

\begin{tabular}{|c|c|c|c|c|}
\hline \multirow[b]{3}{*}{$\begin{array}{l}\text { Features of } \\
\text { lesions }\end{array}$} & \multicolumn{4}{|c|}{ Histopathological outcome } \\
\hline & \multicolumn{2}{|c|}{ Benign lesions } & \multicolumn{2}{|c|}{ Malignant lesions } \\
\hline & $\begin{array}{l}11-15 \mathrm{~mm} \\
(n=309)\end{array}$ & $\begin{array}{l}\leq 10 \mathrm{~mm} \\
(n=318)\end{array}$ & $\begin{array}{l}11-15 \mathrm{~mm} \\
(n=19)\end{array}$ & $\begin{array}{l}\leq 10 \mathrm{~mm} \\
(n=33)\end{array}$ \\
\hline \multirow[t]{2}{*}{ Hypoechogenicity } & 117 & 147 & 12 & 24 \\
\hline & $37.9 \%$ & $46.2 \%$ & $63.2 \%$ & $72.7 \%$ \\
\hline \multirow{2}{*}{$\begin{array}{l}\text { Solitary } \\
\quad \text { occurrence }\end{array}$} & 58 & 51 & 6 & 13 \\
\hline & $18.8 \%$ & $16.0 \%$ & $31.6 \%$ & $39.4 \%$ \\
\hline \multirow{2}{*}{$\begin{array}{l}\text { Presence of } \\
\quad \text { microcalcifications }\end{array}$} & 9 & 5 & 7 & 5 \\
\hline & $2.9 \%$ & $1.6 \%$ & $36.8 \%$ & $15.2 \%$ \\
\hline \multirow{2}{*}{$\begin{array}{l}\text { Intranodular } \\
\quad \text { vascular pattern }\end{array}$} & $32 / 83$ & $27 / 64$ & $3 / 6$ & $2 / 9$ \\
\hline & $38.6 \%$ & $42.2 \%$ & $50.0 \%$ & $22.2 \%$ \\
\hline \multirow[t]{2}{*}{ Height/width $\geq 1^{\mathrm{b}}$} & $5 / 28$ & $4 / 26$ & $7 / 16$ & $20 / 33$ \\
\hline & $17.9 \%$ & $15.4 \%$ & $43.8 \%$ & $60.6 \%$ \\
\hline \multirow[t]{2}{*}{ Palpable } & 163 & 89 & 11 & 8 \\
\hline & $52.8 \%$ & $28.0 \%$ & $57.9 \%$ & $24.2 \%$ \\
\hline
\end{tabular}

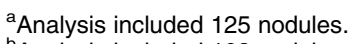

${ }^{\text {b} A n a l y s i s ~ i n c l u d e d ~} 103$ nodules. have led to aspiration of $98.0 \%$ of lesions with cancer while lowering the number of examinations by $24.3 \%$. In the same group (SN), the sensitivity over $90 \%$ was also found for the selection including all hypoechoic lesions and those with height-to-width ratio $\geq 1$. With such selection criteria, specificity would be $46.3 \%$ and the number of FNABs would be lowered by $28.2 \%$. In the group of nodules with diameters not exceeding $10 \mathrm{~mm}$, such selection criteria (hypoechogenicity and height-to-width ratio $\geq 1$ ) would preserve $90 \%$ sensitivity while specificity would be as low as $34.6 \%$, and the number of FNABs would be lowered by $22.1 \%$.

On the other hand, if the selection criteria included all lesions that were solitary or with microcalcifications or with shape ratio $\geq 1$, with hypoechogenicity taken away, the number of performed biopsies would fall by $49.5 \%$ (49.2 in nodules $\leq 10 \mathrm{~mm}$ ), specificity would rise to $77.8 \%$ (76.9 in nodules $\leq 10 \mathrm{~mm})$ with the sensitivity at the level of $81.6 \%(81.8 \%$ in nodules $\leq 10 \mathrm{~mm})$. However, hypoechogenicity was the only feature (among analysed ones), which significantly differed between invasive cancers (with extracapsular growth or nodal involvement) and those limited to the thyroid gland. The invasive malignant lesions were hypoechoic in US examination more frequently than other cancers -75.8 vs $47.6 \% ; P<0.05$. These differences were even more noticeable in the SN group; all small invasive cancers were hypoechoic. In the whole analysed material, extrathyroidal growth was observed in $34.4 \%$ of the malignant lesions $(48.6 \%$ in the $\mathrm{LN}$ group and $24.5 \%$ in the SN group, $P<0.05)$ and in $28.6 \%$ of the cancers not exceeding $10 \mathrm{~mm}$.

In the LN group, the selection criteria based on the shape of lesions and hypoechogenicity were less sensitive than in the SN group, but they allowed further reduction in the number of performed FNABs. The most sensitive criteria in the group LN appeared to be those 
including echogenicity, the shape of lesion and the presence of calcifications. The examination of all hypoechoic lesions or those containing calcifications or with height to width ratio $\geq 1$ would lead to a drop in numbers of FNABs by $56.1 \%$ while keeping high sensitivity and specificity (83.9 and $72.4 \%$ respectively).

\section{Discussion}

Our analysis of the usefulness of the US examination and palpation in selection of thyroid lesions for FNAB was limited to the cases verified by post-operative histopathological examination to assure higher reliability of the results. It should be kept in mind that in cases of FNAB outcomes verified against clinical follow-up only, some false negative results of FNAB may be undiscovered. On the other hand, our data were not significantly biased by possible exclusion of clinically benign nodules in that way as the predominating indication for surgical treatment was multinodular goitre. Clinically benign lesions accompanying suspected nodules were also analysed.

That analysis showed the hypoechogenicity, the presence of microcalcifications and the shape with height-to-width ratio $\geq 1$ to be independent features suggesting malignant lesions, irrespective of their size. The significance of hypoechogenicity was repeatedly reported already $(6,8,10,19-27)$. Similarly, many authors confirmed the role of microcalcifications in the selection of nodules for $\operatorname{FNAB}(5,6,10,11,20-25$, 27-29). The shape of lesions has not been much analysed so far. Some authors evaluated the ratio of the long to short axis of a lesion $(15,30)$, others the anterior-posterior dimension-to-width ratio (6, 20, 22). These reports showed that malignant nodules are more spherical, with the height-to-width ratio $\geq 1$. The shape indicators can possibly reflect the differences in the stiffness between thyroid cancers and benign thyroid lesions (31).

In our material, the solitary occurrence was also indicative of the necessity of FNAB in the case of small lesions. Others questioned the usefulness of this feature $(10,11)$, but it has been confirmed in some reports $(15,25)$ that malignant nodules turn out to be more frequently solitary than benign ones.

Like some other authors, we have found that the most sensitive feature of malignancy is hypoechogenicity, both for small and large lesions. Interestingly, in our material, all invasive microcarcinomas (with the signs of extrathyroidal growth or with spread to lymph nodes) were hypoechoic in the US examination. The role of hypoechogenicity, in revealing aggressive variants of microcarcinomas, was also indicated by Barbaro et al. 2005 (19). Unfortunately, the specificity of this feature is low, especially in SN. The most specific single feature is the presence of microcalcifications in the lesion $(6,10$, $11,20,24,27)$. It increases tenfold the risk of cancer. However, in nodules not exceeding $10 \mathrm{~mm}$, the sensitivity of microcalcifications tended to be lower than in larger lesions. Similar results were obtained by Moon et al. 2008 (20). Less but still significantly predictive is the shape index. Our analysis shows that the features describing the shape of lesion are useful mainly in the diagnostics of SNs. Similar results with respect to the ratio of long to short axis of a lesion reported Berker et al. 2008 (30). The shape of larger lesions is a less sensitive feature probably because

Table 3 Indices of efficiency of features useful in the selection of nodules for fine-needle aspiration biopsy (FNAB) with respect to the size of lesions.

\begin{tabular}{|c|c|c|c|c|}
\hline \multirow[b]{2}{*}{ Features of lesions } & \multirow[b]{2}{*}{ Index (\%) } & \multicolumn{3}{|c|}{ Size of lesions } \\
\hline & & LN & All SN & Only nodules $\leq 10 \mathrm{~mm}$ \\
\hline \multirow{5}{*}{ Hypoechogenicity } & Sensitivity & 52.3 & 69.2 & 72.7 \\
\hline & Specificity & 77.8 & 57.9 & 53.8 \\
\hline & PPV & 19.8 & 12.0 & 14.0 \\
\hline & NPV & 93.9 & 95.8 & 95.0 \\
\hline & Percentage of FNAB performed & 25.1 & 44.2 & 48.7 \\
\hline \multirow{5}{*}{ Presence of microcalcifications } & Sensitivity & 29.5 & 23.1 & 15.2 \\
\hline & Specificity & 95.7 & 97.8 & 98.4 \\
\hline & PPV & 41.9 & 46.2 & 50.0 \\
\hline & NPV & 92.8 & 93.9 & 91.8 \\
\hline & Percentage of FNAB performed & 6.7 & 3.8 & 2.8 \\
\hline \multirow[t]{5}{*}{ Height/width $\geq 1$} & Sensitivity & 29.0 & 55.1 & 60.6 \\
\hline & Specificity & 94.7 & 83.3 & 84.6 \\
\hline & PPV & 69.2 & 75.0 & 83.3 \\
\hline & NPV & 76.6 & 67.2 & 62.9 \\
\hline & Percentage of FNAB performed & 12.1 & 35.0 & 40.7 \\
\hline \multirow[t]{5}{*}{ Solitary occurrence } & Sensitivity & 34.1 & 36.5 & 39.4 \\
\hline & Specificity & 73.2 & 82.6 & 84.0 \\
\hline & PPV & 11.8 & 14.8 & 20.3 \\
\hline & NPV & 91.3 & 94.0 & 93.4 \\
\hline & Percentage of FNAB performed & 27.5 & 18.9 & 27.6 \\
\hline
\end{tabular}


Table 4 The results of multivariate logistic regression analysis of the features suggestive of malignant thyroid nodules. The models were analysed separately for large (LN) and small (SN) lesions. Only features statistically significant in univariate analysis were included in the models of logistic regression.

\begin{tabular}{llcccc}
\hline $\begin{array}{l}\text { Size } \\
\text { of lesions }\end{array}$ & Feature of lesions & Odds ratio & $\mathbf{9 5 \%}$ Cl & \multicolumn{2}{c}{$\begin{array}{c}\boldsymbol{\beta} \text {-Coefficient } \\
\text { and s.E.M. }\end{array}$} \\
\hline LN & Hypoechogenicity & 4.02 & $1.29-12.55$ & $<0.02$ & $1.39 \pm 0.57$ \\
& Presence of microcalcifications & 13.10 & $3.49-68.76$ & $<0.005$ & $2.57 \pm 0.83$ \\
& Height/width $\geq 1$ & 8.55 & $1.82-40.06$ & $<0.01$ & $2.14 \pm 0.78$ \\
SN & Hypoechogenicity & 19.18 & $1.02-9.89$ & $<0.05$ & $1.15 \pm 0.57$ \\
& Presence of microcalcifications & 19.12 & $5.27-69.35$ & $<0.005$ & $3.28 \pm 1.12$ \\
& Height/width $\geq 1$ & 8.57 & $2.77-26.53$ & $<0.0005$ & $2.15 \pm 0.57$ \\
& Solitary occurrence & 3.29 & $1.69-6.39$ & $<0.05$ & $1.27 \pm 0.66$ \\
\hline
\end{tabular}

$\mathrm{Cl}$, confidence interval.

such lesions are more frequently partially cystic, and as such are more spherical even if benign.

Our data did not show usefulness of the assessment of blood flow pattern for the selection of small lesions for FNAB. With respect to this feature, the published opinions are contradictory with some reporting that Doppler US is helpful $(11,20,21,23,26,32)$, and others reporting that Doppler US did not satisfactoruy improve diagnostic accuracy $(10,28,33,34)$. Even though the logistic analysis of regression allows classification of intranodular vascular pattern as an independent feature suggesting malignancy, the $\mathrm{OR}$ is several times lower than for other features (21).

Earlier opinions expressed in some reports $(11,22$, 24,27 ) have been substantiated as we did not find any single criterion of selecting lesions for FNAB to be satisfactory. The analysis of usefulness of feature combinations showed that in the group of small lesions, high sensitivity $(>90 \%)$ could be achieved through selecting for FNAB hypoechoic nodules or those with the height-to-width ratio $\geq 1$. Such selection could lower the number of performed biopsies by $28 \%$.
The addition of all solitary nodules and all nodules with microcalcifications would not increase the number of examinations significantly, but would allow for biopsying $98 \%$ of malignant lesions. Similar results were reported by other authors who used the selection criteria as the shape of lesions (evaluated as in our study) jointly with other features from the US examination. Cappelli et al. 2006 showed that 99\% sensitivity can be achieved by aspiration of lesions more tall than wide and possessing at least two of the following features: hypoechogenicity, blurred margins and calcifications (22). The authors claimed that by applying such criteria, the number of performed FNABs could be lowered by $28 \%$. However, in endemic or postendemic region, with high number of patients with multinodular goitre more rigorous criteria for selection of small lesions for FNAB are needed, which would allow for more significant restriction of the number of performed biopsies (3). Kim et al. 2002 reported that reduction number of performed FNABs by $47 \%$, with $94 \%$ sensitivity and $66 \%$ specificity, could be achieved by selecting lesions fulfilling the above-mentioned shape

Table 5 Efficiency of sets of examined features in the selection of nodules for fine-needle aspiration biopsy (FNAB) with respect to the size of lesions.

\begin{tabular}{|c|c|c|c|c|c|c|c|c|c|}
\hline \multirow[b]{2}{*}{ Criteria of selection for FNAB } & \multicolumn{3}{|c|}{$\begin{array}{l}\text { Percentage of FNAB } \\
\text { performed }\end{array}$} & \multicolumn{3}{|c|}{ Sensitivity (\%) } & \multicolumn{3}{|c|}{ Specificity (\%) } \\
\hline & $\mathrm{LN}$ & All SN & $\begin{array}{c}\text { Only } \\
\text { nodules } \\
\leq 10 \mathrm{~mm}\end{array}$ & LN & All SN & $\begin{array}{c}\text { Only } \\
\text { nodules } \\
\leq 10 \mathrm{~mm}\end{array}$ & LN & All SN & $\begin{array}{c}\text { Only } \\
\text { nodules } \\
\leq 10 \mathrm{~mm}\end{array}$ \\
\hline Hypoechoic or solitary & 43.9 & 66.0 & 69.5 & 58.1 & 85.7 & 84.8 & 61.8 & 51.8 & 42.3 \\
\hline Hypoechoic or microcalcifications & 38.3 & 61.1 & 66.1 & 71.0 & 81.6 & 81.8 & 75.0 & 57.4 & 46.2 \\
\hline Hypoechoic or height/width $\geq 1$ & 38.3 & 71.8 & 77.9 & 67.7 & 91.8 & 90.9 & 73.7 & 46.3 & 34.6 \\
\hline Solitary or microcalcifications & 32.7 & 31.1 & 30.5 & 54.8 & 53.1 & 48.5 & 76.3 & 88.9 & 88.5 \\
\hline Solitary or height/width $\geq 1$ & 31.7 & 41.7 & 42.4 & 51.6 & 59.2 & 63.6 & 76.3 & 74.1 & 76.9 \\
\hline Microcalcifications or height/width $\geq 1$ & 18.7 & 40.8 & 44.1 & 51.6 & 75.5 & 78.8 & 94.7 & 90.7 & 84.6 \\
\hline $\begin{array}{l}\text { Hypoechoic or solitary or } \\
\text { microcalcifications }\end{array}$ & 50.5 & 67.0 & 71.2 & 74.2 & 89.8 & 87.9 & 59.2 & 53.7 & 42.3 \\
\hline $\begin{array}{l}\text { Solitary or microcalcifications } \\
\quad \text { or height/width } \geq 1\end{array}$ & 39.3 & 50.5 & 50.8 & 67.7 & 81.6 & 81.8 & 72.4 & 77.8 & 76.9 \\
\hline $\begin{array}{l}\text { Hypoechoic or microcalcifications or } \\
\text { height/width } \geq 1\end{array}$ & 43.9 & 72.8 & 77.9 & 83.9 & 93.9 & 93.9 & 72.4 & 46.3 & 34.6 \\
\hline Hypoechoic or solitary or height/width $\geq 1$ & 48.6 & 74.8 & 77.9 & 67.7 & 93.9 & 90.9 & 59.2 & 42.6 & 30.8 \\
\hline $\begin{array}{l}\text { Solitary or hypoechoic or } \\
\quad \text { microcalcifications or height/width } \geq 1\end{array}$ & 55.1 & 75.7 & 79.6 & 83.9 & 98.0 & 97.0 & 56.6 & 44.4 & 30.8 \\
\hline
\end{tabular}


criterion or those with microcalcifications, irregular or microlobulated margins or marked hypoechogenicity (relative to the strap muscles in the neck) (6). Those data come from areas of high-iodine supply and low incidence of multinodular goitre. In our epidemiologic situation, similar reduction in the number of performed FNABs is possible on the condition of exclusion of hypoechogenicity from the set of selection criteria. Examination of lesions with height-to-width ratio $\geq 1$ only, or those with microcalcification or solitary ones, would allow limitation of the number of biopsies by $50 \%$ while keeping sensitivity above $80 \%$. However, it would increase the risk of misdiagnosing small invasive thyroid cancers. It is possible that application of 'marked hypoechogenicity' feature would allow avoidance of that risk. In the present study, as the data on the type of margin were not available in many cases, margins of lesions were not analysed. However, it should be stressed that there are significant differences in the definition of suspected appearance of borders. Some researchers, such as Nam-Gong et al. 2004, suggested that ill-defined nodules were important for predicting malignancies, while others (Kim et al. 2002, Cappelli et al. 2006, 2007 and Kang et al. 2004; 5, 6, 10, 21, 22) suggested that irregular margins were important. Moreover, some authors reported that the presence of blurred margins was not significantly linked to malignancy of lesions $(8,25,28)$, or that well-defined margins were a common sonographic feature in papillary carcinomas (23).

Most diagnostic algorithms suggest performing FNAB for all lesions with diameters over $15 \mathrm{~mm}$, even in the absence of any features suggesting the increased risk of cancer (12-14). But in the case of large multinodular goitre, it is necessary to select large lesions for biopsy as well. The present study showed that in the case of large nodules, the usefulness of sonographic features in selecting lesions for FNAB was less satisfactory than in the case of SN. The sensitivity of selection of nearly $84 \%$ could be achieved by biopsying all hypoechoic or containing microcalcifications lesions or with the shape index $\geq 1$, which would lower the number of FNAB by more than $55 \%$.

It is also worth mentioning that in the majority of the reports, the influence of nodule's size on the optimal set of features for selecting lesions for FNAB was not investigated. Only Cappelli et al. (2006) observed that the associations of US features with malignancy were similar in groups of large and small lesions (22). On the other hand, Lyshchik et al. 2005 and Berker et al. 2008 found that the usefulness of sonographic features in selecting lesions for FNAB in the group of larger nodules was lower than in the group of smaller ones, and that for thyroid nodules larger than $15 \mathrm{~mm}$ (Lyshchik) or than $10 \mathrm{~mm}$ (Berker) the only reliable criterion of cancer was hypoechogenicity $(26,30)$. Moon et al. 2008 reported that a set of US features suggestive for malignancy (i.e. the presence of at least one of the findings including taller than wide shape, spiculated margin, hypoechogenicity and the presence of calcifications) showed lower sensitivity and higher specificity for nodules $>10 \mathrm{~mm}$ than for smaller nodules, which is in concordance with our data (20).

In conclusion, the obtained results provide rationale for using features from the US examination, such as the shape of lesion (with height-to-width ratio $\geq 1$ ), hypoechogenicity, the presence of microcalcifications and solitary occurrence in selecting nodules for FNAB. However, it should be considered that these features have different predictive value in diagnosing malignancy and different sensitivity and specificity in respect of nodule size. If keeping high sensitivity of preoperative diagnostic is a primary consideration, the optimal set of small lesions that should be biopsied includes all lesions presenting at least one of the above-mentioned features. In the case of large nodules, the sonographic features are less sensitive in selecting lesions for FNAB than in the case of SN, but they still can be applied for a reduction in the number of performed FNABs in endemic or post-endemic areas. Between large nodules, those primarily selected for FNAB should include hypoechoic, containing microcalcifications or more tall than wide lesions. However, one should remember that epidemiological situation (i.e. iodine supply) may significantly affect the specificity and sensitivity of these features.

It should be stressed that although the set of US features proposed in this study for small lesions is wider than that for larger lesions, it does not mean that in our opinion FNAB of small lesions (of several $\mathrm{mm}$ in diameter) should be performed more frequently than in the case of large nodules. It only shows what US features should be considered to obtain the maximal sensitivity of the diagnostics. Small lesions presenting with such features should be biopsied or followed by repeated US examinations. That was discussed by Mazzaferri \& Sipos 2008 who indicated that US examinations are a better strategy than FNAB in the follow-up of small lesions not exceeding $5 \mathrm{~mm}$, because US features suggesting necessity of FNAB produce high rates of false positive results, and cytologic specimens are frequently inadequate in the case of such small lesions (35). The results of our earlier studies show that it is particularly indicated to follow up small thyroid lesions by repeated US examination in endemic or postendemic areas. In such areas, the efficiency of FNAB is lower in the case of small lesions $(5-10 \mathrm{~mm})$ than in the case of larger ones. One of the reasons is higher rate of multiple nodules in a goitre that makes the proper selection of lesions more difficult (3). It is reasonable to follow up small suspected lesions by repeated US examinations also because of the increased chances of early detection of small invasive cancers, on account of examination of lesion's relation to the thyroid capsule and evaluation of lymph nodes in the neck $(36,37)$. Some investigators suggest that such data from US examination may be useful in the selection of optimal 
treatment strategy, and according to Ito et al. 2003 careful US examinations may even allow refraining from surgical treatment in some cases of papillary microcancers (36).

An important limitation of our study is its retrospective design. Thus, it was not possible to extract information on all analysed US features in some cases. The images from US examinations had not been archived and it was not possible to re-evaluate them. On the other hand, the retrospective design excluded any influence of histopathological diagnosis on interpretation of US images.

\section{Declaration of interest}

There is no conflict of interest that could be perceived as prejudicing the impartiality of the research reported.

\section{Funding}

This work was supported by the Medical University of Lodz (503-1107-6).

\section{References}

1 Ezzat S, Sarti DA, Cain DR \& Braunstein GD. Thyroid incidentalomas. Prevalence by palpation and ultrasonography. Archives of Internal Medicine $1994 \mathbf{1 5 4} 1838-1840$.

2 Tan GH \& Gharib H. Thyroid incidentalomas: management approaches to nonpalpable nodules discovered incidentally on thyroid imaging. Annales of Internal Medicine 1997126 226-231.

3 Slowinska-Klencka D, Popowicz B, Lewinski A, Sporny S \& Klencki M. The fine-needle aspiration biopsy efficacy of small thyroid nodules in the area of recently normalized iodine supply. European Journal of Endocrinology 2008159 747-754.

4 Bennedbæk FN \& Hegedús L. Management of the solitary thyroid nodule: results of a North American survey. Journal of Clinical Endocrinology and Metabolism 200085 2493-2498.

5 Kang HW, No JH, Chung JH, Min YK, Lee MS, Lee MK, Yang JH \& Kim KW. Prevalence, clinical and ultrasonographic characteristics of thyroid incidentalomas. Thyroid 200414 29-33.

6 Kim EK, Park CS, Chung WY, Oh KK, Kim DI, Lee JT \& Yoo HS. New sonographic criteria for recommending fine-needle aspiration biopsy of nonpalpable solid nodules of the thyroid. American Journal of Roentgenology 2002178 687-691.

7 Kim SJ, Kim EK, Park CS, Chung WY, Oh KK \& Yoo HS. Ultrasoundguided fine-needle aspiration biopsy in nonpalpable thyroid nodules: is it useful in infracentimetric nodules? Yonsei Medical Journal 200344 635-640.

8 Leenhardt L, Hejblum G, Franc B, Fediaevsky LD, Delbot T, Le Guillouzic D, Menegaux F, Guillausseau C, Hoang C, Turpin G \& Aurengo A. Indications and limits of ultrasound-guided cytology in the management of nonpalpable thyroid nodules. Journal of Clinical Endocrinology and Metabolism 199984 24-28.

9 Lin JD, Chao TC, Huang BY, Chen ST, Chang HY \& Hsueh C. Thyroid cancer in the thyroid nodules evaluated by ultrasonography and fine-needle aspiration cytology. Thyroid $2005 \mathbf{1 5}$ 708-717.

10 Nam-Goong IS, Kim HY, Gong G, Lee HK, Hong SJ, Kim WB \& Shong YK. Ultrasonography-guided fine-needle aspiration of thyroid incidentaloma: correlation with pathological findings. Clinical Endocrinology 200460 21-28.

11 Papini E, Guglielmi R, Bianchini A, Crescenzi A, Taccogna S, Nardi F, Panunzi C, Rinaldi R, Toscano V \& Pacella CM. Risk of malignancy in nonpalpable thyroid nodules: predictive value of ultrasound and color-Doppler features. Journal of Clinical Endocrinology and Metabolism 200287 1941-1946.

12 AACE/AME Task Force on Thyroid Nodules. American Association of Clinical Endocrinologists and Associazione Medici Endocrinologi medical guidelines for clinical practice for the diagnosis and management of thyroid nodules. Endocrine Practice 200612 63-102.

13 Cooper DS, Doherty GM, Haugen BR, Kloos RT, Lee SL, Mandel SJ, Mazzaferri EL, McIver B, Sherman SI \& Tuttle RM. The American Thyroid Association Guidelines Taskforce. Management guidelines for patients with thyroid nodules and differentiated thyroid cancer. Thyroid 200616 109-142.

14 Pacini F, Schlumberger M, Dralle H, Elisei R, Smit JW \& Wiersinga W. European Thyroid Cancer Taskforce. European consensus for the management of patients with differentiated thyroid carcinoma of the follicular epithelium. European Journal of Endocrinology $2006 \mathbf{5 4} 787-803$.

15 Alexander EK, Marqusee E, Orcutt J, Benson CB, Frates MC, Doubilet PM, Cibas ES \& Atri A. Thyroid nodule shape and prediction of malignancy. Thyroid 200414 953-958.

16 Tae HJ, Lim DJ, Baek KH, Park WC, Lee YS, Choi JE, Lee JM, Kang MI, Cha BY, Son HY, Lee KW \& Kang SK. Diagnostic value of ultrasonography to distinguish between benign and malignant lesions in the management of thyroid nodules. Thyroid $2007 \mathbf{1 7}$ $461-466$.

17 Feldt-Rasmussen U. Prevalence and types of thyroid cancer as a function of iodine intake. In The Thyroid and Environment, pp 187-192. Eds F Péter, W Wiersinga \& U Hostalek, Stuttgart, New York: Verlag Schattauer, 2000.

18 Szybinski Z, Delange F, Lewinski A, Podoba J, Rybakowa M, Wasik R, Szewczyk L, Huszno B, Golkowski F, Przybylik-Mazurek E, Karbownik M, Zak T, Pantoflinski J, Trofimiuk M \& Kinalska I. A programme of iodine supplementation using only iodised household salt is efficient - the case of Poland. European Journal of Endocrinology 2001144 331-337.

19 Barbaro D, Simi U, Meucci G, Lapi P, Orsini P \& Pasquini C. Thyroid papillary cancers: microcarcinoma and carcinoma, incidental cancers and non-incidental cancers - are they different diseases? Clinical Endocrinology 200563 577-5781.

20 Moon WJ, Jung SL, Lee JH, Na DG, Baek JH, Lee YH, Kim J, Kim HS, Byun JS \& Lee DH. Benign and malignant thyroid nodules: US differentiation - multicenter retrospective study. Radiology 2008 $247762-770$.

21 Cappelli C, Castellano M, Pirola I, Cumetti D, Agosti B, Gandossi E \& Agabiti Rosei E. The predictive value of ultrasound findings in the management of thyroid nodules. Quarterly Journal of Medicine: An International Journal of Medicine 2007100 29-35.

22 Cappelli C, Castellano M, Pirola I, Gandossi E, De Martino E, Cumetti D, Agosti B \& Rosei EA. Thyroid nodule shape suggests malignancy. European Journal of Endocrinology $200615527-31$.

23 Chan BK, Desser TS, McDougall IR, Weigel RJ \& Jeffrey RB Jr. Common and uncommon sonographic features of papillary thyroid carcinoma. Journal of Ultrasound in Medicine 200322 1083-1090.

24 Frates MC, Benson CB, Charboneau JW, Cibas ES, Clark OH, Coleman BG, Cronan JJ, Doubilet PM, Evans DB, Goellner JR, Hay ID, Hertzberg BS, Intenzo CM, Jeffrey RB, Langer JE, Larsen PR, Mandel SJ, Middleton WD, Reading CC, Sherman SI \& Tessler FN. Society of Radiologists in Ultrasound. Management of thyroid nodules detected at US: Society of Radiologists in Ultrasound consensus conference statement. Radiology 2005237 794-800.

25 Frates MC, Benson CB, Doubilet PM, Kunreuther E, Contreras M, Cibas ES, Orcutt J, Moore FD Jr, Larsen PR, Marqusee E \& Alexander EK. Prevalence and distribution of carcinoma in patients with solitary and multiple thyroid nodules on sonography. Journal of Clinical Endocrinology and Metabolism 200691 3411-3417. 
26 Lyshchik A, Drozd V, Demidchik Y \& Reiners C. Diagnosis of thyroid cancer in children: value of gray-scale and power Doppler US. Radiology 2005235 604-613.

27 Peccin S, de Castro JA, Furlanetto TW, Furtado AP, Brasil BA \& Czepielewski MA. Ultrasonography: is it useful in the diagnosis of cancer in thyroid nodules? Journal of Endocrinological Investigation 200225 39-43.

28 Iannuccilli JD, Cronan JJ \& Monchik JM. Risk for malignancy of thyroid nodules as assessed by sonographic criteria: the need for biopsy. Journal of Ultrasound in Medicine 200423 1455-1464.

29 Rago T, Di Coscio G, Basolo F, Scutari M, Elisei R, Berti P, Miccoli P, Romani R, Faviana P, Pinchera A \& Vitti P. Combined clinical, thyroid ultrasound and cytological features help to predict thyroid malignancy in follicular and Hupsilonrthle cell thyroid lesions: results from a series of 505 consecutive patients. Clinical Endocrinology 200766 13-20.

30 Berker D, Aydin Y, Ustun I, Gul K, Tutuncu Y, Işik S, Delibasi T \& Guler S. The value of fine-needle aspiration biopsy in subcentimeter thyroid nodules. Thyroid 200818 603-608.

31 Lyshchik A, Higashi T, Asato R, Tanaka S, Ito J, Mai JJ, PellotBarakat C, Insana MF, Brill AB, Saga T, Hiraoka M \& Togashi K. Thyroid gland tumor diagnosis at US elastography. Radiology $2005237202-211$.

32 Levine RA. Value of Doppler ultrasonography in management of patients with follicular thyroid biopsy specimens. Endocrine Practice 200612 270-274.
33 Frates MC, Benson CB, Doubilet PM, Cibas ES \& Marqusee E. Can color Doppler sonography aid in the prediction of malignancy of thyroid nodules? Journal of Ultrasound in Medicine 200322 127-131.

34 Rago T, Vitti P, Chiovato L, Mazzeo S, De Liperi A, Miccoli P, Viacava P, Bogazzi F, Martino E \& Pinchera A. Role of conventional ultrasonography and color flow-Doppler sonography in predicting malignancy in 'cold' thyroid nodules. European Journal of Endocrinology 1998138 41-46.

35 Mazzaferri EL \& Sipos J. Should all patients with subcentimeter thyroid nodules undergo fine-needle aspiration biopsy and preoperative neck ultrasonography to define the extent of tumor invasion? Thyroid $2008 \mathbf{1 8} 597-602$.

36 Ito Y, Uruno T, Nakano K, Takamura Y, Miya A, Kobayashi K, Yokozawa T, Matsuzuka F, Kuma S, Kuma K \& Miyauchi A. An observation trial without surgical treatment in patients with papillary microcarcinoma of the thyroid. Thyroid $2003 \mathbf{1 3}$ 381-387.

37 Kwak JY, Kim EK, Youk JH, Kim MJ, Son EJ, Choi SH \& Oh KKL. Extrathyroid extension of well-differentiated papillary thyroid microcarcinoma on US. Thyroid 200818 609-614.

Received 8 March 2009

Accepted 10 April 2009 